\title{
Efektifitas Reaktor Pengolahan Limbah Cair Laboratorium Menggunakan Arang Kulit Buah Kakao (Theobroma cacao)
}

\section{Effectiveness Of Reactor Treatment Of Laboratory Liquid Waste With Charcoal Of Cocoa Pods Husk (Theobroma cocoa)}

\author{
Pabbenteng ${ }^{*}$, Puspitasari $^{2}$ \\ ${ }^{1}$ Jurusan Teknik Kimia, Politeknik Negeri Ujung Pandang, Indonesia \\ ${ }^{2}$ Jurusan Teknik Kimia, Politeknik Negeri Ujung Pandang, Indonesia \\ Email : ${ }^{1}$ pabbenteng@poliupg.ac.id (HP: 081355186397),2²puspa.dj@gmail.com
}

Direview : 30 Juli 2020

Diterima : 20 Agustus 2020

\begin{abstract}
Abstrak
Reaktor pengolah limbah cair merupakan alat yang digunakan untuk mengurangi zat pengotor dalam limbah termasuk logam berat. Laboratorium menjadi sentral penelitian dan menghasilkan limbah yang bervariasi, baik fisika, kimia maupun biologi. Kulit kakao merupakan limbah pertanian dan menjadi salah satu limbah organik yang volumenya melimpah sehingga mengganggu lingkungan yaitu menimbulkan bau yang tidak sedap dan media bagi serangga. Kulit kakao berpotensi diolah menjadi arang karena memiliki kandungan sellulosa, hemi sellulosa dan lignin yang tinggi. Penggunaaan arang kulit kakao sebagai adsorben logam $\mathrm{Cu}^{2+}$ yang terdapat dalam limbah laboratorium merupakan solusi untuk mengurangi pencemaran lingkungan dengan memanfaatkan limbah pertanian untuk mengolah limbah laboratorium.Tujuan penelitian ini adalah menentukan kondisi optimum reaktor pengolahan limbah meliputi diameter partikel adsorben, tinggi adsorben dalam reaktor serta laju alir limbah yang melewati kolom reaktor. Sistem pengolahan limbah dengan sistem kontinyu dan analisa limbah sebelum dan sesudah melewati reaktor menggunakan AAS. Preparasi arang kulit kakao yaitu dengan pemanasan pada suhu $150^{\circ} \mathrm{C}$ selama lebih kurang 4 jam. Kondisi optimum reaktor terjadi pada diameter partikel 120 mesh, ketinggian adsorben $15 \mathrm{~cm}$ dan laju $68,39 \mathrm{~mL} /$ detik pada kolom reaktor berdiameter 2 inch serta tinggi $50 \mathrm{~cm}$. Efektifitas reaktor menggunakan arang kulit kakao pada kondisi optimum sebesar 30,056 $\%$.
\end{abstract}

Kata kunci : Adsorpsi, Biocharcoal, Kulit Kakao, Logam Berat $\mathrm{Cu}^{2+}$.

Abstract

The liquid waste processing reactor is a toll used to reduce impurities in waste, including heavy metals. the laboratory is the center of research and produce various wastes, both physical, chemical and biological. Cocoa shells is an agricultural waste and is one the organic waste whose volume is abundant, which the disturbs the environment, which causes unpleasant odors and a medium for insects. Cocoa shells have the potential to be processed into charcoal because the contain high cellulose, hemicellulose and lignin. The use of cocoa shells charcoal as an adsorbent for $\mathrm{Cu}^{2+}$ contained in laboratory waste is a solution to reduce environmental pollution by utilizing agriculutural waste to treat laboratory waste. The purpose this research was to determine of the optimum conditions for the waste treatment reactor including the diameter of the adsorbent particles, the height of the adsorbent in the reactor and the flow rate of waste passing through the reactor column. Waste treatment system with a continuous system and waste analysis before and after passing through the reactor using AAS.Preparation of cocoa shell charcoal by heating at a temperature of $140{ }^{\circ} \mathrm{C}$ for about 4 hours. The optimum conditions for the reactor occurredat a particle diameter of 120 mesh, an adsorbent height of $25 \mathrm{~cm}$ and a rate of $68,39 \mathrm{~mL} / \mathrm{second}$ in the reactor column with a diameter of 2 inches and height of 50 $\mathrm{cm}$.The effectiveness of the reactor using cocoa shell charcoal at the optimum conditions.

Keywords : Adsorption, Biocahrcoal, Cocoa shell, Heavy metal $\mathrm{Cu}^{2+}$

DOI : 10.35970/jppl.v2i2.338

Corresponding Author : pabbenteng@poliupg.ac.id 


\section{PENDAHULUAN}

Reaktor pengolah limbah cair terdiri dari piva PVC dengan diameter 2 inch dengan model vertikal serta aliran dari bawah keatas. Reaktor optimum pada ketinggian adsorben $20 \mathrm{~cm}$ dengan laju alir 21,94 mL/detik terhadap parameter fisika meliputi TSS, TDS dan $\mathrm{pH}$. Limbah dialirkan melewati reaktor dengan menggunakan pompa dan kecepatan alir diatur menggunakan katub pada bagian inlet reaktor (Pabbenteng \& Alwina, 2020). Reaktor dapat dilihat pada Gambar 1 berikut ini.

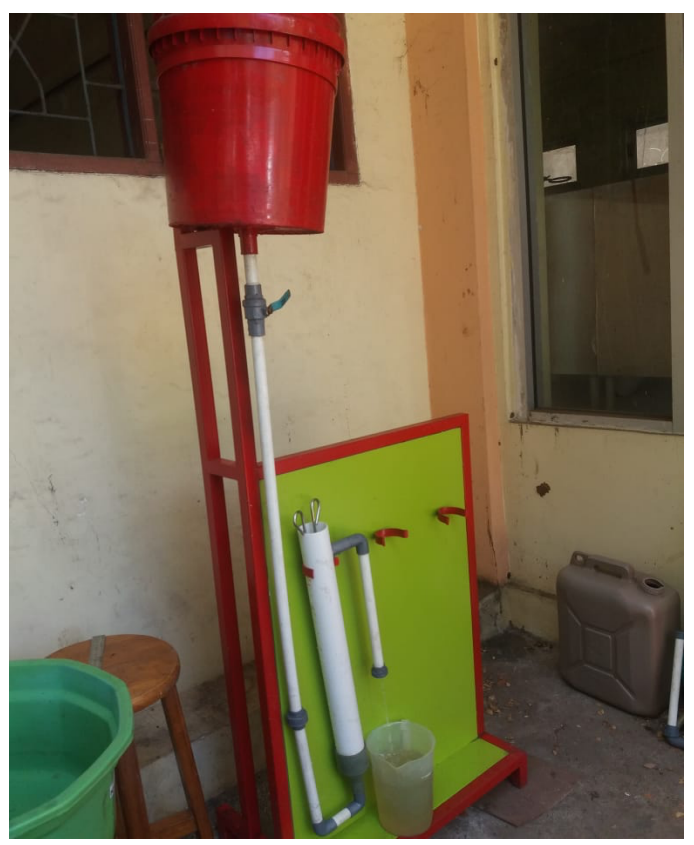

Gambar 1. Reaktor Pengolah Limbah Cair

Laboratorium adalah suatu tempat dimana dilakukan kegiatan percobaan, pengukuran, penelitian atau riset ilmiah yang berhubungan dengan ilmu sains (kimia, biologi, fisika) dan ilmu-ilmu lainnya (Emda, 2014). Limbah Laboratorium banyak mengandung senyawa organik dan anorganik yang berasal dari sisa bahan kimia yang digunakan dalam praktium (Audiana, Apriani, \& Kadaria, 2017).

Arang (biocharcoal) kulit kakao baik digunakan untuk menyerap logam berat karena memiliki pori. Kulit kakao berpotensi diolah menjadi arang (biocharcoal) karena memiliki kandungan hemisellulosa, sellulosa dan lignin yang tinggi. Hal ini juga yang menjadi potensi untuk diolah menjadi arang aktif karena memiliki kandungan karbon yang cukup banyak. Penyerapan terhadap logam Timbal $(\mathrm{Pb})$ efektif pada ukuran partikel adsorben pada 200 mesh pada sistem batch (Podala, Walanda, \& Napitupulu, 2015).

Biosorpsi adalah proses penyerapan ion-ion logam oleh biomaterial melibatkan interaksi ionik, polar, interaksi gabungan dan mineralisasi antara ion logam dan biopolymer pembentuk sel (Mawardi et al., 2014) . Adsorpsi adalah proses phyco-kimia dimana zat yang disebut adsorbat terakumulasi pada antarmuka padatan yang disebut adsorben. Adsorbsi adalah salah satu teknik yang sering diterapkan pada pengolahan air, karena metode ini cocok untuk konsentrasi logam yang rendah dan biaya murah (Yusoff et al., 2014).

Proses adsorbsi terdiri dari 3 fasa yaitu zat menyerap kebagian luar adsorben, zat pindah ke pori-pori adsorben, dan zat menyerap ke dinding bagian dalam adsorben (Mohammed, 2011). Proses adsorpsi bisa terjadi secara fisika dan juga secara kimia. Proses adsorpsi bisa ditentukan berdasarkan persamaan Isotermal Languir dan Freundlich. 
Logam berat merupakan pengelompokan unsur-unsur logam yang mempunyai berat jenis lebih dari $5 \mathrm{gr} / \mathrm{cm} 3$. Contoh logam berat adalah Kromium (Cr), Tembaga (Cu), Besi (Fe), Mangan (Mn), Molybdenum (Mo), Nikel (Ni), Timbal ( $\mathrm{Pb}$ ), Zirconium ( $\mathrm{Zr}$ ) dan Seng ( $\mathrm{Zn}$ ) (Firdaus, 2012). Pengolahan limbah cair yang mengandung logam berat dengan metode adsorpsi menggunakan bahan alami disebut sebagai pengolahan dengan teknologi hijau. Keuntungan dari teknologi hijau ini adalah biaya murah, ketersediaan bahan baku, pengoperasian yang mudah dan efisien (Etorki et al., 2014). Pemanfaatan limbah kulit kakao sebagai adsorben merupakan implementasi dari teknologi hijau.

Tembaga adalah logam berat yang terdapat di lingkungan yang mudah terakumulasi dalam rantai makanan secara biologi apabila terkontamisai dengan makanan, air dan udara. Toksisitas tembaga dapat menyebabkan dampak akut pada manusia, seperti anemia, gagal hati dan ginjal, kaget, koma dan bahkan kematian (Kamble et al., 2018). Keracunan akut karena jumlah garam yang mengandung tembaga dapat mengakibatkan hemestemesis, melena, koma dan penyakit kuning. Oleh karena itu, pengurangan kandungan tembaga dalam limbah cair sebelum dibuang ke lingkungan baik ke badan air maupun di tanah sesuai standar yang ada (Maheswari, Pattabhi, \& Malathi, 2017).

Tujuan penelitian ini adalah menentukan kondisi optimum reaktor terhadap limbah laboraorium meliputi ukuran partikel dan ketinggian adsorben serta laju alir limbah yang melewati reaktor terhadap penurunan kandungan logam $\mathrm{Cu}$.

\section{METODE PENELITIAN}

\subsection{Waktu dan Lokasi Penelitian}

Penelitian ini dilakukan selama lebih kurang 4 bulan di Laboratorium Pengolahan Limbah Jurusan Teknik Kimia Politeknik Negeri Ujung Pandang.

\subsection{Alat dan Bahan Penelitian}

Alat yang digunakan pada penelitian ini yaitu reaktor dan instrument untuk analisa kandungan logam $\mathrm{Cu}$ serta alat pendukung lainnya. Kandungan logam $\mathrm{Cu}$ diukur menggunakan AAS merk Parking Elmert. Alat pendukung lainnya meliputi tungku pengarangan, oven, kruser/ blender, neraca analitik dan alat gelas yang digunakan saat preparasi sampel untuk pengujian kandungan logam $\mathrm{Cu}$.

Bahan yang digunkan meliputi limbah Laboratorium dan arang kulit buah kakao (Theobroma cocoa). Kulit buah kakao (Theobroma cocoa) diperoleh dari daerah Palopo dan Bone lalu diarangkan menggunakan tungku pengarangan di Jurusan Teknik Kimia Politeknik Negeri Ujung Pandang.

\subsection{Prosedur Penelitian}

Kulit kakao dibersihkan dari kotoran tanah dan dedaunan dan dikeringkan dibawah sinar matahari selaman 4-7 hari dilanjutkan proses pengarangan. Arang (biocharcoal) tersebut diblender atau dikruser dan diayak dengan ukuran 18 mesh, 30 mesh, 40 mesh, 60 mesh, 120 mesh dan 160 mesh. Pengaktifan arang (biocharcoal) kulit kakao tersebut dilakukan secara fisika yaitu pemanasan dalam oven pada suhu $105^{\circ} \mathrm{C}$ selama $4-5$ jam.

Limbah Laboratorium diperoleh saluran pembuangan, sisa bahan kimia dan ditampung dalam bak penampungan.

Penentuan kondisi optimum reaktor dengan menggunakan adsorben arang kulit buah kakao (Theobroma cocoa). Sampel awal diambil sebelum sampel dialirkan melalui kolom adsorpsi sebanyak $50 \mathrm{ml}$ untuk dianalisa kandungan $\mathrm{Cu}$ (II). Arang (biocharcoal) kulit kakao dimasukkan dalam kolom rekator dengan ketinggian $15 \mathrm{~cm}$ dengan laju alir 20 $\mathrm{mL} /$ detik. Perlakuan ini dilakukan terhadap 5 jenis ukuran partikel adsorben yaitu yaitu

DOI : 10.35970/jppl.v2i2.338

Corresponding Author : pabbenteng@poliupg.ac.id 
18 mesh, 30 mesh, 40 mesh, 60 mesh, 120 mesh dan 160 mesh.. Sampel yang telah melewati kolom adsorpsi (reaktor) ditampung dan dilakukan analisa kandungan $\mathrm{Cu}$ (II) menggunakan AAS. Ukuran partikel yang optimum yang diperoleh dilanjutkan pada 5 jenis laju alir limbah yaitu yaitu $0 \mathrm{~mL} / \operatorname{detik}($ sampel awal); $3,98 \mathrm{~mL} /$ detik; 11,18 $\mathrm{mL} /$ detik; 31,96 mL/detik; 68,39 $\mathrm{mL} /$ detik serta $124,14 \mathrm{~mL} /$ detik pada ketinggian adsorben yang tetap yaitu $20 \mathrm{~cm}$. Laju alir yang optimum dilanjutkan dengan 5 jenis ketinggian adsorben yaitu $0 \mathrm{~cm}, 10 \mathrm{~cm}, 15 \mathrm{~cm}, 20 \mathrm{~cm}$ dan $25 \mathrm{~cm}$ pada kondisi laju alir dan diameter partikel yang optimum. Pengujian logam $\mathrm{Cu}$ (II) dengan AAS (Atomic Absorption Spectroscopy) berdasarkan SNI 06-6989.6-2004 (Indonesia, 2004).

\section{HASIL DAN PEMBAHASAN}

Hasil yang diperoleh dalam penelitian ini mencakup diameter partikel, laju alir serta ketinggian adsorben optimum. Reaktor dengan diameter 2 inch dan tinggi $50 \mathrm{~cm}$ dan terbuat dari pipa PVC. Kondisi optimum terjadi pada diameter partikel adosrben arang kulit kakao 120 mesh, laju alir 68,39 mL/detik serta ketinggian adsorben $15 \mathrm{~cm}$.

Hasil penelitian untuk perlakuan variasi diameter partikel dapat dilihat pada Tabel 1 . Kondisi optimum terjadi pada diameter partikel arang kulit kakao 120 mesh efektif menyerap logam $\mathrm{Cu}^{2+}$ hingga 82,090 \% yang terdapat dalam limbah Laboratorium.

Tabel 1.Variasi diameter partikel terhadap penyerapan logam $\mathrm{Cu}^{2+}$

\begin{tabular}{|c|c|c|c|}
\hline $\begin{array}{c}\text { Ukuran } \\
\text { partikel } \\
(\mathrm{mesh})\end{array}$ & $\begin{array}{c}\text { Kandungan } \\
\mathrm{Cu}^{2+} \\
(\mathrm{ppm})\end{array}$ & $\begin{array}{c}\text { Penurunan } \\
\mathrm{Cu}^{2+} \\
(\mathrm{ppm})\end{array}$ & $\begin{array}{c}\text { Daya serap } \\
(\%)\end{array}$ \\
\hline Sampel awal (0) & 2,775 & 2,775 & 0 \\
\hline 18 & 1,971 & 0,804 & 28,973 \\
\hline 30 & 1,290 & 1,485 & 53,514 \\
\hline 40 & 1,237 & 1,538 & 55,423 \\
\hline 60 & 0,979 & 1,796 & 64,721 \\
\hline 120 & 0,497 & 2,278 & 82,090 \\
\hline 160 & 0,509 & 2,266 & 81,658 \\
\hline
\end{tabular}

Tabel 1 menunjukkan penyerapan logam $\mathrm{Cu}^{2+}$ meningkat seiring kenaikan ukuran partikel. Pada diameter arang kulit kakao 120 mesh mengalami kondisi optimum yaitu penyerapan mencapai $82,090 \%$. Pada ukuran partikel 160 mesh mengalami penurunan daya serap karena pada ukuran 120 mesh terjadi penyerapan optimum. Pada proses Batch, umumnya penyerapan optimum terjadi pada ukuran 200 mesh, hal ini berbeda dengan pada saat proses kontinyu. Penyerpan logam $\mathrm{Pb}^{2+}$ dengan biocharcoal kulit kakao pada proses Batch terjadi pada ukuran 200 mesh (Podala et al., 2015) . Pada proses kontinyu, ukuran partikel optimum terjadi pada ukuran 120 mesh. Semakin kecil ukuran partikel semakin besar luas permukaan kontak, sehingga adsorben berupa serbuk lebih efektif dibandingkan dengan bentuk padatan (Zarkasi, Moelyaningrum, \& Ningrum, 2018). Ukuran partikel optimum dilanjutkan untuk menentukan kondisi laju alir umpan terhadap efektifitas penyerapan arang kulit kakao terhadap logam $\mathrm{Cu}^{2+}$.

Kondisi optimum pada variasi laju alir umpan terhadap penyerapan $\mathrm{Cu}^{2+}$ oleh arang kulit kakao terjadi pada laju alir $68,39 \mathrm{~mL} /$ detik. Pada laju alir yang lebih besar mengalami penuruan daya serap arang kulit kakao terhadap logam $\mathrm{Cu}^{+}$. Tabel 2 menunjukkan tingkat penyerapan adsorben terhadap logam $\mathrm{Cu}^{2+}$ berdasarkan laju alir umpan.

DOI : 10.35970/jppl.v2i2.338

Corresponding Author : pabbenteng@poliupg.ac.id 
Tabel 2.Variasi laju alir terhadap penyerapan logam $\mathrm{Cu}^{2+}$

\begin{tabular}{|c|c|c|c|}
\hline $\begin{array}{c}\text { Laju alir } \\
(\mathrm{mL} / \mathrm{dtk})\end{array}$ & $\begin{array}{c}\text { Kandungan } \\
\mathrm{Cu}^{2+} \\
(\mathrm{ppm})\end{array}$ & $\begin{array}{c}\text { Penurunan } \\
\mathrm{Cu}^{2+} \\
(\mathrm{ppm})\end{array}$ & $\begin{array}{c}\text { Daya } \\
\text { serap (\%) }\end{array}$ \\
\hline $\begin{array}{c}\text { Sampel } \\
\text { awal }(0)\end{array}$ & 1,450 & 1,450 & 0 \\
\hline 3.98 & 1,431 & 0,0019 & 0,131 \\
\hline 11,18 & 1,412 & 0,038 & 2,621 \\
\hline 31,96 & 1,275 & 0,175 & 12,069 \\
\hline 68,39 & 0,995 & 0,455 & 31,379 \\
\hline 124,14 & 1,007 & 0,443 & 30,552 \\
\hline
\end{tabular}

Laju alir optimum terjadi pada $68,39 \mathrm{~mL} /$ detik, hal ini disebabkan karena kontak antara adsorben dan limbah yang melewati kolom reaktor terjadi secara optimum. Pusaran aktif dari adsorben maksimal pada kecepatan tersebut, sehingga penyerapan menjadi maksimal, dan pada laju yang lebih besar kemungkinan adsorben mengalami desorbsi. Faktor yang mempengaruhi penyerapan logam $\mathrm{Cu}$ oleh adsorben adalah pusaran aktif telah jenuh, konsentrasi ion logam dan kejenuhan adsorben (Setiawan, Napitupulu, \& Walanda, 2018).

Perlakuan selanjutnya yaitu penentuan ketinggian adsorben optimum. Perlakuan ini dilakukan pada kondisi diameter partikel optimum ( 120 mesh) dan laju alir optimum $(68,39 \mathrm{~mL} /$ detik). Data penentuan kondisi ketinggian adsorben optimum ditunjukkan pada Tabel 3 berikut ini.

Tabel 3. Variasi ketinggian adsorben terhadap penyerapan ion logam $\mathrm{Cu}^{2+}$

\begin{tabular}{|c|c|c|c|}
\hline $\begin{array}{c}\text { Tinggi } \\
\text { Adsorben } \\
(\mathrm{cm})\end{array}$ & $\begin{array}{c}\text { Kandungan } \\
\mathrm{Cu}^{2+} \\
(\mathrm{ppm})\end{array}$ & $\begin{array}{c}\text { Penurunan } \\
\mathrm{Cu}^{2+} \\
(\mathrm{ppm})\end{array}$ & $\begin{array}{c}\text { Daya } \\
\text { serap } \\
(\%)\end{array}$ \\
\hline $\begin{array}{c}\text { Sampel awal } \\
(0)\end{array}$ & 8,258 & 8,258 & 0 \\
\hline 10 & 6,822 & 1,436 & 17,389 \\
\hline 15 & 5,776 & 2,482 & 30,056 \\
\hline 20 & 5,986 & 2,272 & 27,513 \\
\hline 25 & 7,412 & 0,846 & 10,245 \\
\hline
\end{tabular}

Pada Tabel 3 menunjukkan kondisi optimum pada variasi ketinggian adsorben terjadi pada $15 \mathrm{~cm}$ dengan diameter kolom reaktor yaitu 2 inch serta ketinggian reaktor $50 \mathrm{~cm}$. Tingkat penyerapan logam pada ketinggian adsorben $15 \mathrm{~cm}$ yaitu 30,056\%. Kondisi inilah yang optimum pada penelitian ini, yaitu ketinggian adsorben $15 \mathrm{~cm}$, laju 68,39 $\mathrm{mL} /$ detik dengan ukuran partikel adsorben 120 mesh pada proses kontinyu.

Kapasitas adsorpsi arang tergantung dari karakteristik arangnya, yaitu tekstur (luas permukaan, ukuran pori), gugus fungsi serta sifat fisikanya (kadar abu) (Saniyyah, 2014). Penyerapan logam $\mathrm{Cu}$ oleh suatu adsorben tergantung pada proses pengolahannya (batch atau kontinyu) dan jenis adsorbennya. 


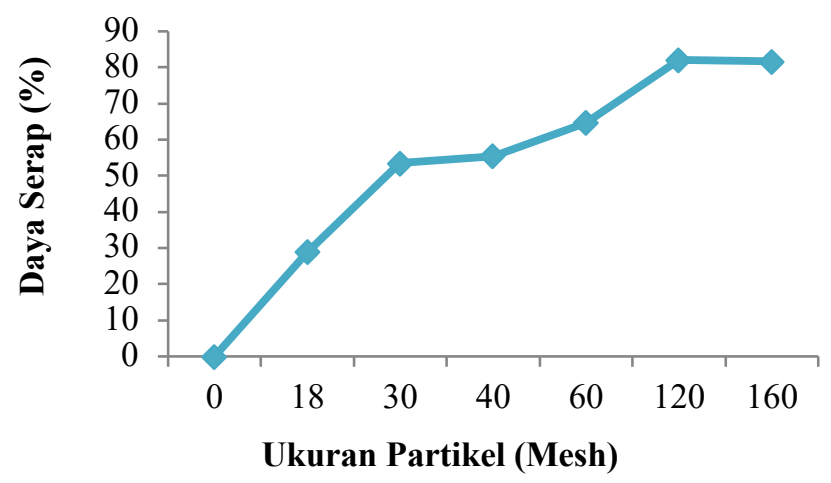

Gambar 1. Hubungan Diameter Partikel Terhadap Penyerapan $\mathrm{Cu}^{2+}$ Pada Proses Kontinyu.

Pada Gambar 2 menunjukkan ukuran partikel optimum pada proses kontinyu terjadi pada 120 mesh dengan aktifasi secara fisika.. Hal ini berbeda pada proses sistem Batch umumnya optimum pada diameter partikel 200 mesh dengan aktifasi secara kimia. Penyerapan logam Cd dengan arang kulit kakao optimum pada ukuran partikel 200 mesh, aktifasi kimia yaitu dengan penambahan $\mathrm{ZnCl}_{2}$ pada proses sistem Batch (Masitoh \& Sianta, 2013).

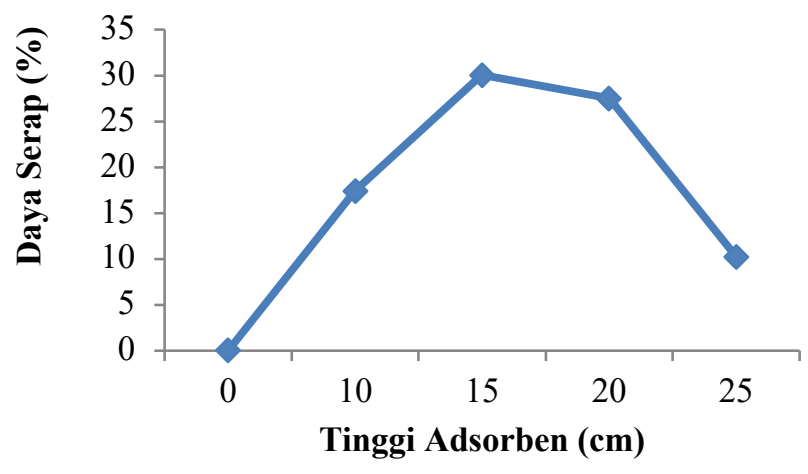

Gambar 2. Hubungan Tinggi Adsorben Terhadap Penyerapan $\mathrm{Cu}^{2+}$ Pada Proses Kontinyu.

Gambar 2 menunjukkan semakin bertambahnya ketinggi adsorben, penyerapan semakin meningkat. Pada kondisi optimum yaitu pada ketinggian $15 \mathrm{~cm}$ mencapai puncak penyerapan yaitu 30,056\%. Hal ini disebabkan karena kerapatan sel adsorben terhadap terhadap logam $\mathrm{Cu}^{2+}$ efektif sehingga interaksi pusaran aktif dinding sel adsorben dengan logam $\mathrm{Cu}^{2+}$ dalam limbah tersebut (Podala et al., 2015).

Pada ketinggian $20 \mathrm{~cm}$ mengalami penurunan penyerarapan. Hal ini disebabkan karena adsorben sudah dalam kondisi jenuh. 


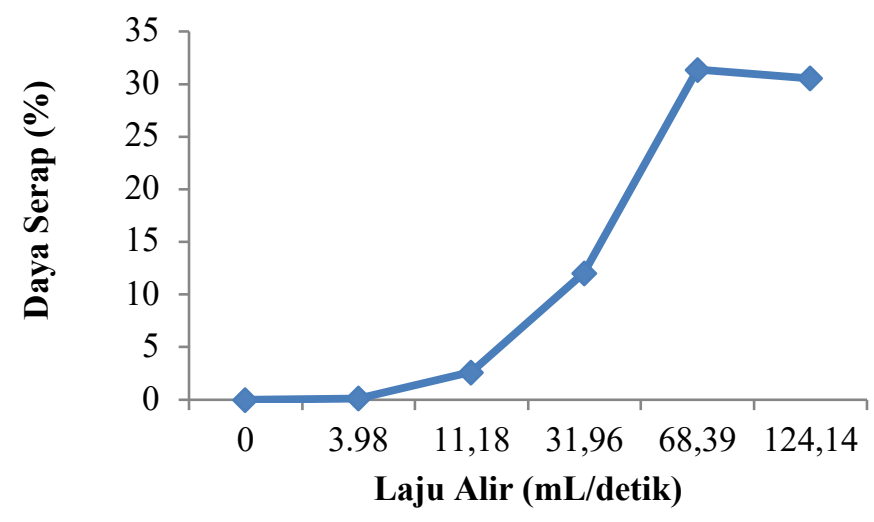

Gambar 3. Hubungan Laju Alir Terhadap Penyerapan $\mathrm{Cu}^{2+}$ Pada Proses Kontinyu.

Pada Gambar 3 menunjukkan kondisi optimum dari proses penyerapan logam $\mathrm{Cu}^{2+}$ oleh arang kulit kakao menggunakan reaktor secara kontinyu terjadi pada laju alir 68,39 $\mathrm{mL} /$ detik, tinggi adsorben $15 \mathrm{~cm}$ dan diameter partikel 120 mesh. Pada laju 124,14 $\mathrm{mL} /$ detik mengalami penurunan daya serap arang kulit kakao terhadap logam $\mathrm{Cu}^{2+}$.

Penurunan daya serap adsorben pada laju $124,14 \mathrm{~mL} /$ detik. Hal ini disebabkan karena hampir semua permukaan adsorben telah berikatan dengan ion logam (Hayati \& Sawir, 2017). Pada proses kontinyu dan proses batch kondisi penyerapan optimum berbeda.

\section{KESIMPULAN}

Arang kulit kakao dapat digunakan sebagai adsorben logam $\mathrm{Cu}^{2+}$ pada sistem kontinyu. Kondisi optimum terjadi pada diameter partikel 120 mesh, laju alir 68,39 $\mathrm{mL} /$ detik serta ketinggian adsorben $15 \mathrm{~cm}$ pada kolom reaktor dengan diameter sebesar 2 inch dan tinggi kolom sebesar $50 \mathrm{~cm}$. Daya serap adsorpsi pada kondisi optimum sebesar $30,056 \%$.

\section{SARAN}

Pada penelitian selanjutnya disarankan untuk menambah panjang kolom reaktor serta kolom reaktor diganti dengan akrilic yang bening, sehingga jika terjadi penyumbatan bisa terdeteksi secara langsung.

\section{PENGHARGAAN}

Penulis mengucapkan terima kasih dan penghargaan sebesar-besarnya kepada pihak Kementerian Pendidikan Dan Kebudayaan Direktorat Jenderal Pendidikan Tinggi, dalam hal ini Direktur Sumber Daya Bapak Mohammad Sofwan Effendi yang telah memberikan dana Hibah penelitian tahun 2020. Penulis juga mengucapkan terima kasih kepada Direktur Politeknik Negeri Ujung Pandang, Ketua Jurusan Teknik Kimia serta rekanrekan di jurusan Teknik Kimia Politeknik Negeri Ujung Pandang yang banyak membantu dalam proses penyelesain penelitian ini. Tak lupa keluarga tercinta dan terkhusus kepada orang tua kami. 
Jurnal Pengendalian Pencemaran Lingkungan (JPPL)

Vol.2 No.02 September 2020

\section{DAFTAR PUSTAKA}

Audiana, M., Apriani, I., \& Kadaria, U. (2017). Pengolahan Limbah Cair Laboratorium Teknik Lingkungan Dengan Koagulasi Dan Adsorpsi Untuk Menurunkan COD, Fe Dan Pb. Jurnal Teknologi Lahan Basah, 5(1), 1-10.

Emda, A. (2014). Laboratorium Sebagai Sarana Pembelajaran Kimia Dalam Meningkatkan Pengetahuan Dan Keterampilan Kerja Ilmiah. Lantanida Journal, 2(2).

Etorki, A. M., El-rais, M., Mahabbis, M. T., \& Moussa, N. M. (2014). Removal of Some Heavy Metals from Wastewater by Using of Fava Beans. American Journal of Analytical Chemistry, 5(March), 225-234.

Firdaus, M. L. (2012). Studi perbandingan berbagai adsorben sintetis dan alami untuk mengikat logam berat. Semnas Pendidikan Sains, 3.

Hayati, U. P., \& Sawir, H. (2017). Pemanfaatan Limbah Kulit Buah Kakao Sebagai Adsorben Untuk Penyerapan Ion Logam Kromium ( VI ). Jurnal Sains Dan Teknologi, 17(1).

Indonesia, S. N. (2004). Air dan air limbah - Bagian 6: Cara uji tembaga (Cu) dengan Spektrofotometri Serapan Atom (SSA)-nyala.

Kamble, P. N., Bodade, R. G., Sagar, A. K., Pondhe, G. M., Gaikwad, V. B., \& Mane, A. V. (2018). Removal of Copper ( II ) Using Bio-adsorbents from Prepared Aqueous Solution. Nature Environment and Pollution Technology An International Quarterly Scientific Journal Original, 17, 215-222.

Maheswari, P., Pattabhi, S., \& Malathi, S. (2017). Adsorption Of CU ( II ) Ion From Aqueous Solution Using Acid Treated Sago Waste As An Adsorbent. European Journal of Pharmaceutical and Medical Research, 4(11), 296-301.

Masitoh, Y. F., \& Sianta, M. M. (2013). Pemanfaatan Arang Aktif Kulit Buah Coklat (Thebroma cacao.L) Sebagai Adsorben Logam Berat Cd(II) Dalam Pelarut Air. UNESA Juornal of Chemistry, 2(2), 23-28.

Mawardi, Munaf, E., Kosela, S., \& Wibowo, W. (2014). Prmisahan Ion Krom(III) dan Krom(IV) Dalam Larutan Dengan Menggunakan Biomassa Alga Hujau Spirogysa Subsalsa Sebagai Biosorben. Reaktor, 15(1), 27-36.

Mohammed, F. M. (2011). Modelling and Design of Water Treatment Processes Using Adsorption and Electrochemical Regeneration. Tesis, Engineering and Physical Sciences. University of Manchester.

Pabbenteng, \& Alwina, E. (2020). Desain Reaktor Pengolahan Limbah Cair Laboratorium. Jurnal Pengendalian Pencemaran Lingkungan (JPPL), 2(1), 15-21.

Podala, K., Walanda, D. K., \& Napitupulu, M. (2015). Biocharcoal Dari Kulit Kakao (Theobroma cacao L) Untuk mengadsorpsi Ion Logam Timbal. J.Akademika Kim, 4(August), 136-142.

Saniyyah, N. (2014). Sekam Padi untuk Menyerap Ion Logam Tembaga dan Timbal dalam Air Limbah. Valesni, 4(1).

Setiawan, I. K. A., Napitupulu, M., \& Walanda, D. K. (2018). Biocharcoal Dari Kulit Rambutan (Nephelium Lappceum L) Sebagai Adsorben Zink Dan Tembaga. J.Akademika Kim, 7(November), 193-198.

Yusoff, S. N. M., Kamari, A., Putra, W. P., Ishak, C. F., Mohamed, A., Hashim, N., \& Isa, I. (2014). Removal of $\mathrm{Cu}$ ( II ), Pb ( II ) and Zn ( II ) Ions from Aqueous Solutions Using Selected Agricultural Wastes: Adsorption and Characterisation Studies. Journal of Environmental Protection, 5(March), 289-300.

Zarkasi, K., Moelyaningrum, A. D., \& Ningrum, P. T. (2018). Penggunaan Arang Aktif Kulit Durian (Durio zibethinus Murr) Terhadap Tingkat Adsorpsi Kromium((Cr6+) Pada Limbah Batik. EFEKTOR, 5, 67-73.

DOI : 10.35970/jppl.v2i2.338

Corresponding Author : pabbenteng@poliupg.ac.id 
Jurnal Pengendalian Pencemaran Lingkungan (JPPL)

Vol.2 No.02 September 2020

DOI : 10.35970/jppl.v2i2.338

Corresponding Author : pabbenteng@poliupg.ac.id 